Article

\title{
Impact of Silicon Carbide Devices on the Dynamic Performance of Permanent Magnet Synchronous Motor Drive Systems for Electric Vehicles
}

\author{
Xiaofeng Ding *, Min Du, Jiawei Cheng, Feida Chen, Suping Ren and Hong Guo
}

School of Automation Science and Electrical Engineering, BeiHang University, Beijing 100191, China; dumin@buaa.edu.cn (M.D.); chengjiawei0218@126.com (J.C.); dege820@126.com (F.C.); rsp93_4@126.com (S.R.); guohong@buaa.edu.cn (H.G.)

* Correspondence: dingxiaofeng@buaa.edu.cn; Tel.: +86-10-8233-9498

Academic Editors: Hailong Li and Joe (Xuan) Zhou

Received: 5 January 2017; Accepted: 6 March 2017; Published: 15 March 2017

\begin{abstract}
This paper investigates the impact of silicon carbide ( $\mathrm{SiC}$ ) metal oxide semiconductor field effect transistors (MOSFETs) on the dynamic performance of permanent magnet synchronous motor (PMSM) drive systems. The characteristics of SiC MOSFETs are evaluated experimentally taking into account temperature variations. Then the switching characteristics are firstly introduced into the transfer function of a SiC-inverter fed PMSM drive system. The main contribution of this paper is the investigation of the dynamic control performance features such as the fast response, the stability and the robustness of the drive system considering the characteristics of SiC MOSFETs. All the results of the SiC-drive system are compared to the silicon-(Si) insulated gate bipolar transistors (IGBTs) drive system counterpart, and the SiC-drive system manifests a higher dynamic performance than the Si-drive system. The analytical results have been effectively validated by experiments on a test bench.
\end{abstract}

Keywords: silicon carbide (SiC) MOSFET; silicon (Si) IGBTs; permanent magnet synchronous motor (PMSM); switching characteristics; dynamic performance

\section{Introduction}

Wide band-gap power device materials, such as silicon carbide ( $\mathrm{SiC})$, are drawing increasing attention due to a number of superior qualities they possess, such as high switching-speed, lower specific on-resistance, and higher junction operating temperature capability [1-7]. The application of $\mathrm{SiC}$ in a motor drive inverter can reduce both switching and conduction losses, shorten dead time in a phase-lag, and increase switching frequency, etc. Hence, the SiC-inverter can provide higher efficiency and higher power density in comparison to its silicon ( $\mathrm{Si}$ ) inverter counterpart [8-11], which is benefit for the electric vehicles with limited capacity battery [11,12].

Aside for these inverter-level benefits, the SiC-inverter also affects features of the dynamic performance of a motor drive system, such as fast response, relative stability and robustness, etc. This has not been clearly addressed yet, therefore, this paper investigates the impact of a SiC-inverter on the performance of a motor drive system, which is unlike some previous works that solely considered SiC-inverter systems [13].

Because of its high efficiency and fast response characteristics, permanent magnet synchronous motors (PMSMs) are widely adopted in a host of high performance applications where low torque ripple, high efficiency, and remarkable dynamic response are highly demanded, such as dynamic positioning systems, machine-tool spindle electrical power steering and traction drives in electric vehicles, etc. [14]. Hence, the dynamic performance of a PMSM fed by a SiC voltage source inverter (VSI) is worthy of further investigation. Numerous research activities have been conducted to analyze 
different aspects of the dynamic response, such as frequency response, fast response, relative stability and robustness [15-17].

The dynamic performance analysis of a VSI-fed PMSM is based on state equations, with the $d$ - and $q$-axis components of the stator currents and the rotor flux linkage as state variables [15]. A transfer function of the drive system was developed according to the state equations and control theory [18-20]. Then classical techniques such as Bode plots and Nyquist diagrams were used for analyzing the dynamic performance of the controlled system $[20,21]$. The traditional Bode plots were used to evaluate the frequency response in control engineering [21]. The frequency response manifests the bandwidth and the fast response capability of the system.

Not only an adequate bandwidth promises a fast response ability of a PMSM system, but also sufficient relative stability and robustness guarantee its long-term robust operation. The relative stability of a system can be evaluated by the specified gain- and phase-margins described by Nichols plots of loop transfer functions [22]. In addition, the robustness of the system can be investigated by $\mathrm{H}$-infinity conditions on sensitivity functions $[23,24]$.

The dynamic performance of a motor is mainly related with sampling delay and microprocessor calculation time, control strategies, and the characteristics of a given motor and inverter, etc. Researchers have performed a large amount of valuable work regarding the dynamic performance of the motor drive system [25-27]. In [25], the sampling and microprocessor delay were considering in a transfer function of a drive system to analyze the dynamic performance of a PMSM system. In [26], a synchronous sampling (synchronized with the pulse-width modulation (PWM) carrier) of instantaneous phase current value was adopted in a current feedback loop, which achieved a higher bandwidth than the conventional methods. In [27], the oversampling, namely sampling and controller updating done with a higher rate than the regular sampling methodology counterparts, is adopted to improve the frequency response.

Aside from the sampling delay, the computational effort on the digital signal processor (DSP) also causes a time delay [28-32]. In order to overcome the time delay, some program compensations have been done [28]. In addition to the software program improvements, faster microprocessors were adopted recently to reduce the delay time, such as field-programmable gate arrays (FPGAs), which take advantage of parallel calculations [29-32]. The use of efficient hardware and software allows the control algorithm to be run in less than $10 \mu \mathrm{s}$ [29], which is less than the computation time of a DSP28335 (usually more than $50 \mu$ s in our previous projects).

In addition to the sampling and microprocessor analysis, more research activities are currently conducted on the applied control strategies for improving the dynamic performance of PMSM drive systems [15,28,33-37]. In [15], a new predictive direct torque control (DTC) method was developed, which is introduced to achieve the fastest dynamic response in the transient state compared to the conventional DTC method. In this proposed method only the parameters of one voltage vector need to be calculated in contrast with the previous studies where the parameters of two voltage vectors must be calculated, resulting in a lower computational burden. In [28], a proposed controller is based on a combination of deadbeat and direct predictive control techniques for a PMSM drive system. The computational delay was compensated by a modification of the control process. The proposed technique exhibited faster response as well as better robustness than the conventional proportional integral (PI) field-oriented control (FOC) technique. In [33], a per-phase control in the abc-domain was proposed, which requires only one frame transformation execution. Such a control scheme yields excellent sinusoidal current command tracking and disturbance rejection.

Although many advanced control strategies and emerging fast computation microprocessor technologies have been to improve the dynamic performance of the PMSM drive system, few investigations have been done from the viewpoint of SiC-MOSFET characteristics. Hence, the purpose of this study was to explore the impact of SiC-MOSFET switching on the dynamic performance of a PMSM drive system. The SiC-MOSFET characteristics are evaluated experimentally through a double-pulse test (DPT), taking temperature into consideration. The switching performance is applied 
to a physical model of voltage distortion in a SiC-inverter to quantify the distorted voltages. Then, the switching performance of a SiC-MOSFET is firstly introduced into the transfer function of the PMSM drive system. As a result, the fast response, the stability, and the robustness of the system can be conveniently investigated from a control theory point of view. Finally, the analytical results are effectively validated by experiments. All the studies of the SiC-MOSFET drive system are compared to a Si-IGBT drive system counterpart.

The remainder of this paper is organized as follows: in Section 2, the characteristics of the power devices are evaluated by DPT, and the distorted voltage of the inverter is quantitatively calculated. In Section 3, a novel PMSM transfer function is developed, taking into account the switching performance of the power device. In Section 4, the dynamic performances of the PMSM are analyzed based on transfer functions. In Section 5, the experimental setup and the validation are illustrated. Conclusions are drawn in the final section.

\section{Power Devices Characteristics}

In order to analyze the dynamic performance of the PMSM drive system considering the power device characteristics, in this section of the paper we investigate the switching characteristics of a SiC MOSFET (CAS300M12BM2, CREE, Durham, NC, USA) and a Si IGBT (FF400R12KE3, Infineon, Am Campeon, Neubiberg, Germany) by a double-pulse test (DPT). The DPT setup was built as shown in Figure 1, where a DC source voltage $(270 \mathrm{~V})$ is assigned to a leg of the inverter, and the inductors of two phases in the PMSM are adopted as the load inductors. The lower switch of phase-leg is selected as the device under test (DUT). A high precision voltage probe (P5100A, Tektronix, Beaverton, OR, USA) and a TCPA300 current probe (Tektronix, Beaverton, OR, USA) plus a TCP303 are used to measure the voltage $\left(V_{\mathrm{DS}}\right)$ and channel current $\left(I_{\mathrm{C}}\right)$ of the DUT, respectively.

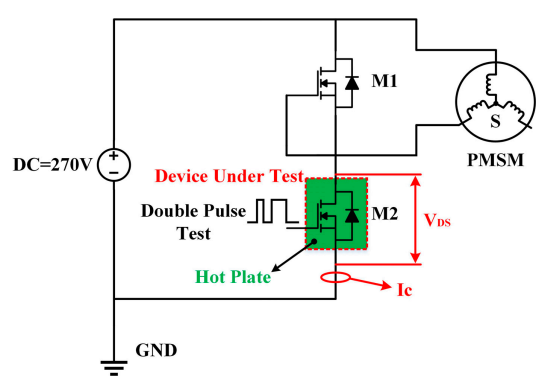

(a)

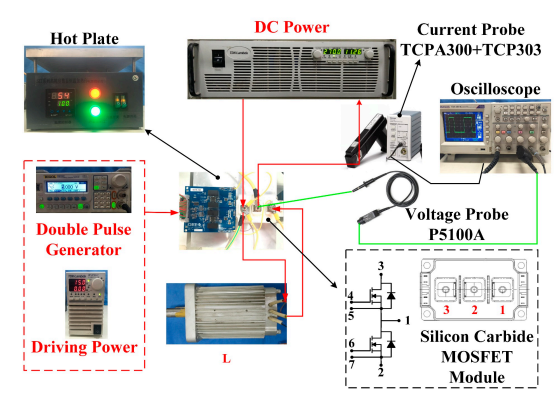

(b)

Figure 1. DPT test bench. (a) Simplified DPT circuit; (b) Actual components in the test bench.

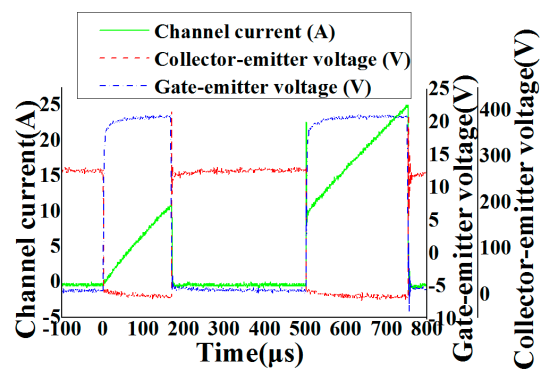

(a)

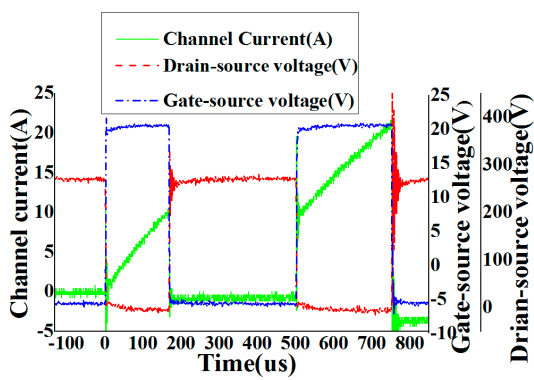

(b)

Figure 2. Total switching transitions. (a) Si IGBT; (b) SiC MOSFET.

This setup is used to characterize the on-state voltage drop, the turn-on and turn-off transient processes. A comparison of the switching waveforms for the Si IGBT and SiC MOSFET are presented in Figure 2. The enlarged figures of turn-on and turn-off transients are shown in Figure 3. The red 
lines show the collector-emitter voltage $\left(V_{\mathrm{CE}}\right)$ for IGBT or drain-source voltage $\left(V_{\mathrm{DS}}\right)$ for the MOSFET. The green lines represent the channel current of the power devices and the blue lines display the waveforms of the gate-drive signals.
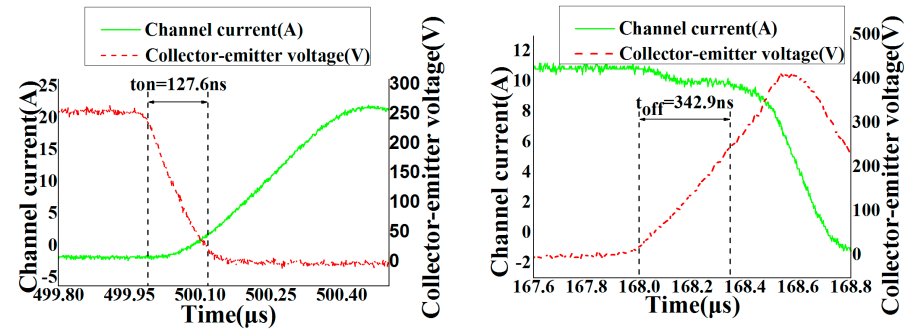

(a)
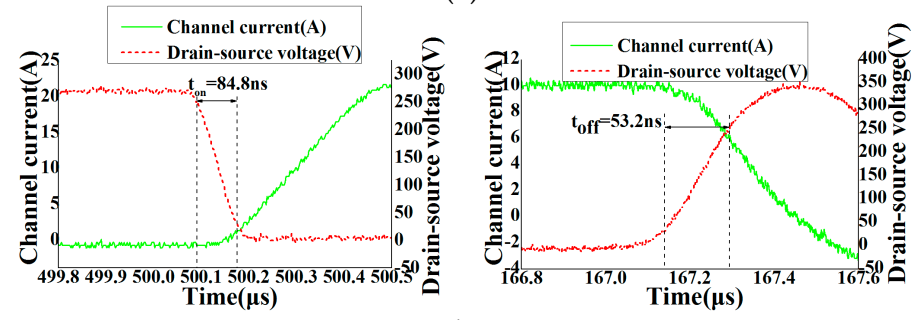

(b)

Figure 3. Turn-on and turn-off trajectories. (a) Si IGBT; (b) SiC MOSFET.

Figure 3 shows that the turn-on and turn-off times of the Si IGBT are $127.6 \mathrm{~ns}$ and $342.9 \mathrm{ns,}$ respectively, when the ambient temperature is $25^{\circ} \mathrm{C}$ and the channel current is $11 \mathrm{~A}$. Both the turn-on and turn-off times of the SiC MOSFET, which are $84.8 \mathrm{~ns}$ and $153.2 \mathrm{~ns}$, correspondingly, are smaller than those of the Si counterpart.

In addition, the accumulation of system losses leads to an increase in the device junction temperature after a long operation time. The characteristics of the devices under different temperatures are systematically explored in this paper, which is helpful to analyze the properties of semiconductor devices in practical applications taking thermal effects into account. Hence, the switching times of both $\mathrm{SiC}$ and $\mathrm{Si}$ are tested at different temperatures applied by a hot plate.

Figure 4 illustrates the switching times of power devices at different temperatures. The turn-off times of Si IGBT increase as the increasing temperature. However, the switching time of SiC MOSFET remains constant under different temperatures. In addition to the switching times of the two devices, the other characteristics of the two devices are also measured as shown in Table 1. The voltage drop of $\mathrm{SiC}$ MOSFET is about $5 \%$ of $\mathrm{Si}$ IGBT. The value of $\mathrm{SiC}$ MOSFET is $44.2 \mathrm{mV}$ and the counterpart of Si IGBT is $832.5 \mathrm{mV}$. The output capacitance of SiC MOSFET is also smaller than that of Si IGBT. These different characteristics are vital for calculating the phase voltage distortions and evaluating the dynamic performances of SiC- and Si-drive system.
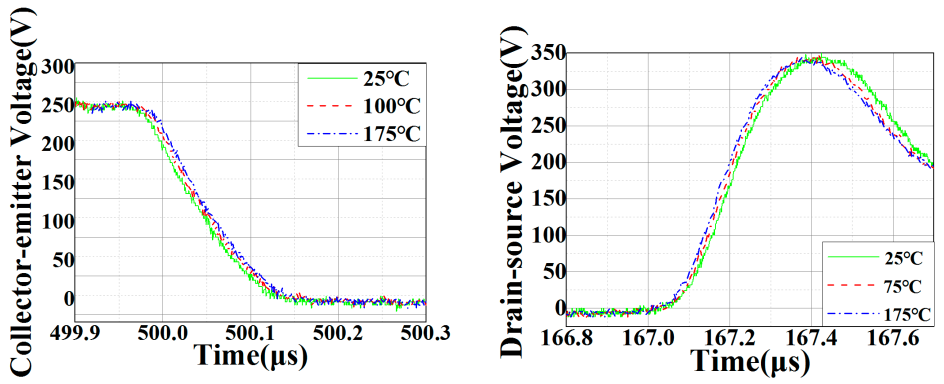

(a)

Figure 4. Cont. 

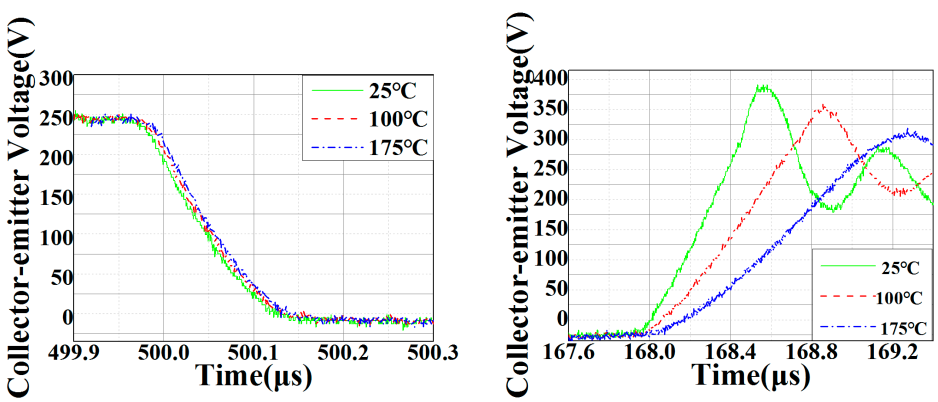

(b)

Figure 4. Switching time of power devices at different temperatures. (a) Si IGBT; (b) SiC MOSFET.

Table 1. Test parameters measured by the DPT.

\begin{tabular}{cccc}
\hline \multirow{2}{*}{ Symbol } & Quantity & \multicolumn{2}{c}{ Value } \\
\cline { 3 - 4 } & & SiC MOSFET & Si IGBT \\
\hline$t_{\text {on }}$ & Turn on time & $84.8 \mathrm{~ns}$ & $127.6 \mathrm{~ns}$ \\
$t_{\text {off }}$ & Turn off time & $153.2 \mathrm{~ns}$ & $342.9 \mathrm{~ns}$ \\
$V_{\mathrm{d}}$ & Voltage drop & $44.2 \mathrm{mV}$ & $832.5 \mathrm{mV}$ \\
$C_{\mathrm{o}}$ & Output capacitance & $12.7 \mathrm{nF}$ & $32.7 \mathrm{nF}$ \\
$\Delta V$ & average voltage distortion & $-2.42 \mathrm{~V}$ & $-3.28 \mathrm{~V}$ \\
\hline
\end{tabular}

In [38,39], the phase voltage distortions of the inverter are developed, taking the dead time, switching time, voltage drop and output capacitance into account. In Figure 5a, the deviation appears in the waveform of the inverter phase voltage. $V_{\text {ref }}$ displays the ideal fundamental phase voltage of the inverter that would result if there were no distortion voltage effects. As the PMSM is an inductive load, the phase current waveform $i$ lags behind $V_{\text {ref }}$ by an angle $\theta^{\prime}$. Since the distortion voltage increases (decreases) the inverter phase voltage for the negative (positive) half cycle of the phase current as shown in Figure 5b, the average voltage distortion over an entire cycle could be illustrated by the square wave in Figure 5 a.

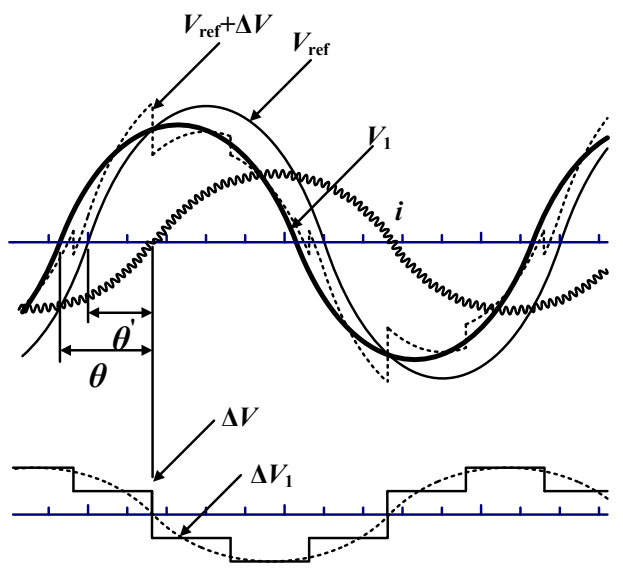

(a)

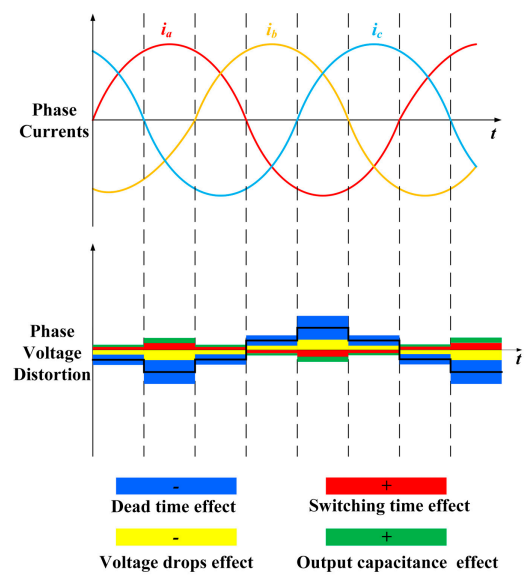

(b)

Figure 5. The voltage distortion and its impact on current. (a) Representation of waveforms of the voltage and current; (b) Average voltage distortion induced by four aspects.

The average voltage distortion is the superposition of $\Delta V$ on the ideal voltage $V_{\text {ref }}$ shown as broken line in Figure $5 \mathrm{a}$. Therefore, the fundamental phase voltage with distortion voltage $V_{1}$ is the sum of $V_{\text {ref }}$ and $\Delta V_{1}$, which is described as a heavy solid curve. When the harmonic components of the 
current are ignored the phase displacement between $V_{1}$ and $i$ corresponds to the fundamental power factor angle of the load. It can be seen that the real fundamental phase voltage differs from the reference one in both the phase and magnitude. Therefore, when the fundamental phase voltage reduces and power factor angle increases, the current will increase to maintain a constant output power.

According to the mathematical model of the phase voltage distortion, less switching times, smaller output capacitances and lower voltage drops of SiC MOSFET will reduce the phase voltage distortion. With a faster switching speed, the dead-time of SiC MOSFET in phase-leg configuration can be reduced, which helps to reduce the phase voltage distortion.

\section{Transfer Functions of a PMSM Drive System Considering Device Characteristics}

In order to conveniently investigate the impact of the power devices' characteristics on the dynamic performance of a PMSM, this paper develops a novel PMSM drive system transfer function taking into account the device characteristics. Then the impacts of SiC-MOSFETs on the fast response, relative stability and robustness of the PMSM drive system are explored based on the proposed transfer function.

\subsection{Transfer Function of the Inverter}

The input signal $u_{\mathrm{c}}$ of inverter originates from a microprocessor (DSP38335), which is $3.3 \mathrm{~V}$ space vector PWM (SVPWM) waveform. Then, the input signal is amplified to a power signal $u_{\mathrm{a}}$ via a driver broad and a power device. A phase lag between $u_{\mathrm{c}}$ and $u_{\mathrm{a}}$ is induced due to the lag of the inverter. Hence, the inverter used in motor drive system can be assumed as a black box with a gain and a phase delay. The simplified transfer function of it could be represented by a first-order lag system [40]:

$$
G_{1}(s)=K_{\mathrm{r}} /\left(\tau_{\mathrm{r}} s+1\right)
$$

where, $K_{\mathrm{r}}=\frac{2}{\pi} u_{\mathrm{a}} / u_{\mathrm{cm}}$ is the inverter gain, $u_{\mathrm{cm}}$ is the maximum gate drive signal voltage, $u_{\mathrm{a}}$ is the maximum phase voltage. $\tau_{\mathrm{r}}$ is delay time constant, depends on the switching cycle $1 / f_{\mathrm{sw}}$, turn-on time $t_{\mathrm{on}}$, turn-off time $t_{\text {off }}$ and the dead time $T_{\mathrm{dt}}$ :

$$
\tau_{\mathrm{r}}=a_{1} / f_{\mathrm{sw}}+a_{2} T_{\mathrm{dt}}+a_{3} t_{\mathrm{on}}+a_{4} t_{\mathrm{off}}
$$

where, $a_{1}, a_{2}, a_{3}, a_{4}$ are the coefficients of the switching cycle, dead time, turn-on time and turn-off time, respectively.

Both the turn-on and turn-off time of $\mathrm{SiC}$ are smaller than those of the Si counterpart as shown in Section 2. The benefit of this is that a smaller dead time duration and a higher switching frequency can be achieved in a SiC-inverter. Hence, the delay time constant $\tau_{\mathrm{r} 1}$ of the SiC-inverter is shorter than that of a Si-inverter according to (2):

$$
\tau_{\mathrm{r} 1}<\tau_{\mathrm{r} 2}
$$

It is known that the distorted voltage of SiC-inverter is less than that of a Si-inverter counterpart as shown in Figure 5. Consequently, the amplitude of the phase voltage of SiC-inverter is higher than that of a Si-inverter when the DC sources are the same ones. Hence, it is concluded that the gain of a $\mathrm{SiC}$-inverter $K_{\mathrm{r} 1}$ is higher than that of a Si-inverter $K_{\mathrm{r} 2}$ :

$$
K_{\mathrm{r} 1}<K_{\mathrm{r} 2}
$$

\subsection{Transfer Function of the Motor and PI Regulator}

The input and output are the command and output currents, respectively. The control strategy of $i_{\mathrm{d}}=0$ is adopted in this drive system. Hence, the tracking characteristic of the q-axis current $i_{\mathrm{q}}$ can 
reflect well the dynamic performance of the system. A simplified equation of the motor voltage is shown in the following equation:

$$
u_{\mathrm{q}}=R i_{\mathrm{q}}+p\left(L_{\mathrm{q}} i_{\mathrm{q}}\right)+\psi_{\mathrm{f}} \omega_{\mathrm{e}}
$$

where, $p$ is a differential operator, $\psi_{\mathrm{f}}$ is the flux linkage of the permanent magnet, $\omega_{\mathrm{e}}$ is the electric angular velocity of the motor. From (5), the transfer function of PMSM in $q$-axis frame is expressed as:

$$
G_{2}(s)=1 /\left(L_{\mathrm{q}} s+R_{\mathrm{a}}\right)
$$

where, $L_{\mathrm{q}}$ is the $q$-axis inductance and $R_{\mathrm{a}}$ is the stator resistance.

Besides, the equation of PI regulator in the time domain is:

$$
u(t)=K_{\mathrm{p}} e(t)+K_{\mathrm{i}} \int e(t) d t
$$

where, $K_{\mathrm{p}}$ and $K_{\mathrm{i}}$ are the proportional and integral coefficients, respectively and $e(t)$ is the error between the reference and feedback signals. The transfer function of the PI regulator can be obtained by a Laplace transform of (7):

$$
G_{3}(s)=K_{\mathrm{p}}\left(\tau_{\mathrm{i}} s+1\right) /\left(\tau_{\mathrm{i}} s\right)
$$

where, $\tau_{\mathrm{i}}=K_{\mathrm{p}} / K_{\mathrm{i}}$.

In conclusion, the current control model of the PMSM drive system is shown in Figure 6. The open-loop transfer function of system can be written as:

$$
G(s)=G_{1}(s) G_{2}(s) G_{3}(s)=\frac{K_{\mathrm{q}} K_{\mathrm{r}} K_{\mathrm{p}}\left(\tau_{\mathrm{i}} s+1\right)}{\tau_{\mathrm{i}} s\left(\tau_{\mathrm{q}} s+1\right)\left(\tau_{\mathrm{r}} s+1\right)}
$$

where, $K_{\mathrm{q}}=1 / R_{\mathrm{a}}, \tau_{\mathrm{q}}=L_{\mathrm{q}} / R_{\mathrm{a}}$.

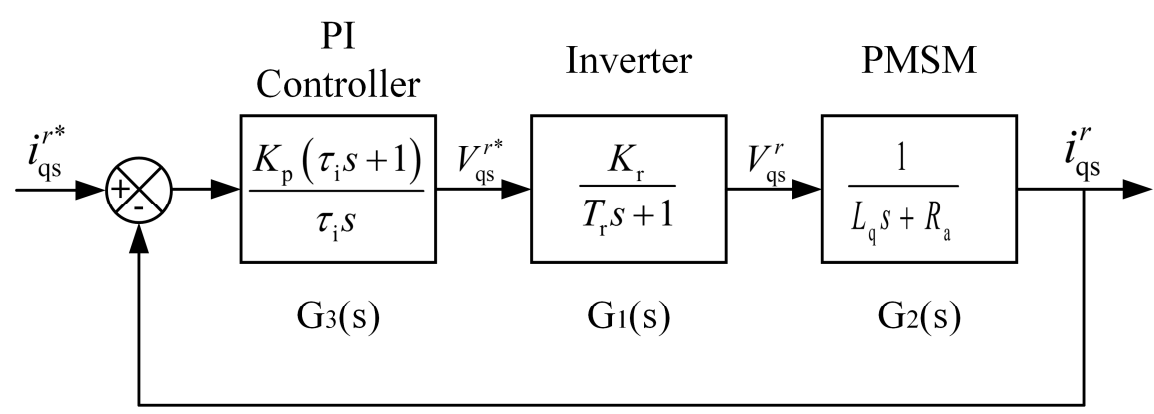

Figure 6. Schematic model of q-axis current of PMSM.

The PI regulator of the $q$-axis current is designed by applying pole zero cancellation, namely setting $\tau_{\mathrm{i}}=\tau_{\mathrm{q}}$ [40]. Thus the closed-loop transfer function is obtained taking the characteristics of devices into account:

$$
G_{c}(s)=\frac{K_{\mathrm{q}} K_{\mathrm{r}} K_{\mathrm{p}}}{\tau_{\mathrm{r}} \tau_{\mathrm{i}} s^{2}+\tau_{\mathrm{i}} s+K_{\mathrm{q}} K_{\mathrm{r}} K_{\mathrm{p}}}=\frac{\omega_{\mathrm{n}}^{2}}{s^{2}+2 \xi \omega_{\mathrm{n}} s+\omega_{\mathrm{n}}^{2}}
$$

where, $\omega_{\mathrm{n}}=\sqrt{K_{\mathrm{q}} K_{\mathrm{r}} K_{\mathrm{p}} / \tau_{\mathrm{r}} \tau_{\mathrm{i}}}$ represents the undamped natural frequency. $\xi=\sqrt{\tau_{\mathrm{i}} / 4 K_{\mathrm{q}} K_{\mathrm{r}} K_{\mathrm{p}} \tau_{\mathrm{r}}}$ represents the damping ratio. 


\section{Dynamic Performance Analysis of the PMSM}

\subsection{Fast Response Performance}

As a basic requirement of industrial applications, an advanced and smart inverter fed PMSM system needs fast response performance. In general, the fast response performance of the control system can be evaluated via the bandwidth and the settling time.

According to (10), the closed-loop frequency characteristic of the system can be expressed as:

$$
G_{\mathrm{c}}(\mathrm{j} \omega)=\frac{i_{\mathrm{qs}}^{r}(j \omega)}{i_{\mathrm{q}}^{r *}(j \omega)}=\frac{\omega_{\mathrm{n}}^{2}}{(j \omega)^{2}+2 \xi \omega_{\mathrm{n}}(j \omega)+\omega_{\mathrm{n}}^{2}}=M_{\mathrm{B}}(\omega) \mathrm{e}^{\mathrm{j} \varphi_{\mathrm{B}}(\omega)}
$$

When the closed-loop amplitude-frequency characteristic $M_{\mathrm{B}}(\omega)$ equals 0.707 times the amplitude at zero-frequency, the corresponding frequency is defined as cut-off frequency $\omega_{b}$, i.e.:

$$
1 / \sqrt{\left(1-\frac{\omega_{\mathrm{b}}^{2}}{\omega_{\mathrm{n}}^{2}}\right)^{2}+\left(2 \xi \frac{\omega_{\mathrm{b}}}{\omega_{\mathrm{n}}}\right)}=0.707
$$

Hence, the relationship among the cut-off frequency $\omega_{b}$, the undamped natural frequency $\omega_{n}$ and the damping ratio $\xi$ can be obtained as:

$$
\omega_{\mathrm{b}}=\omega_{\mathrm{n}} \sqrt{1-2 \xi^{2}+\sqrt{2-4 \xi^{2}+4 \xi^{4}}}
$$

From the monotonicity analysis of (13), it can be concluded that $\omega_{\mathrm{b}}$ decreases as the increase of $\xi$, and increases as $\omega_{n}$ increses. The following equations are obtained by substituting (3) and (4) into (10):

$$
\begin{gathered}
\omega_{\mathrm{n} 1}>\omega_{\mathrm{n} 2} \\
\xi_{1}>\xi_{2}
\end{gathered}
$$

where, $\omega_{\mathrm{n} 1}$ and $\omega_{\mathrm{n} 2}$ represent the undamped natural frequencies of $\mathrm{SiC}$ - and Si-drive systems, respectively. $\xi_{1}$ and $\xi_{2}$ represent the damping ratios of SiC- and Si-drive systems, respectively.

Equations (14) and (15) are substituted into (13), resulting in:

$$
\omega_{\mathrm{b} 1}>\omega_{\mathrm{b} 2}
$$

Hence, compared with the Si-drive system, the SiC-drive system manifests a higher bandwidth leading to a fast response.

In addition, the settling time of the system $t_{\mathrm{s}}$ can be calculated as:

$$
t_{\mathrm{s}} \approx 4 / \xi \omega_{\mathrm{n}}=4 /\left(\sqrt{\tau_{\mathrm{i}} / 4 K_{\mathrm{q}} K_{\mathrm{r}} K_{\mathrm{p}} \tau_{\mathrm{r}}} \cdot \sqrt{K_{\mathrm{q}} K_{\mathrm{r}} K_{\mathrm{p}} / \tau_{\mathrm{r}} \tau_{\mathrm{i}}}\right)=8 \tau_{\mathrm{r}}
$$

From (17), the settling time $t_{\mathrm{s}}$ is directly proportional to the delay time constant $\tau_{\mathrm{r}}$ of the inverter. Hence, the settling time of the SiC-drive system is shorter than that of a Si-drive system according to (3). According to the aforementioned analyzing results and the system parameters shown in Table 2, the Bode plot of the closed-loop transfer functions for the two systems was drawn, as shown in Figure 7. The bandwidth $\omega_{\mathrm{b}}$ is usually defined by $-3 \mathrm{~dB}$ amplitude response in Bode plots for a closed loop drive system. Thanks to the superior switching characteristics of SiC MOSFET, the bandwidth of the $\mathrm{SiC}$-drive system is $1190 \mathrm{~Hz}$, which is higher than the $1090 \mathrm{~Hz}$ of the Si-drive system. 
Table 2. The main parameters of the PMSM drive system.

\begin{tabular}{ccc}
\hline Symbol & Quantity & Value \\
\hline$U_{\mathrm{DC}}$ & Input DC voltage & $270 \mathrm{~V}$ \\
$U_{\mathrm{cm}}$ & Maximum gate driving voltage & $20 \mathrm{~V}$ \\
$L_{\mathrm{q}}$ & q axis inductance & $5.19 \mathrm{mH}$ \\
$R_{\mathrm{a}}$ & Stator resistance & $0.25 \Omega$ \\
$K_{\mathrm{p}}$ & Proportional coefficient & 3.8 \\
\hline
\end{tabular}

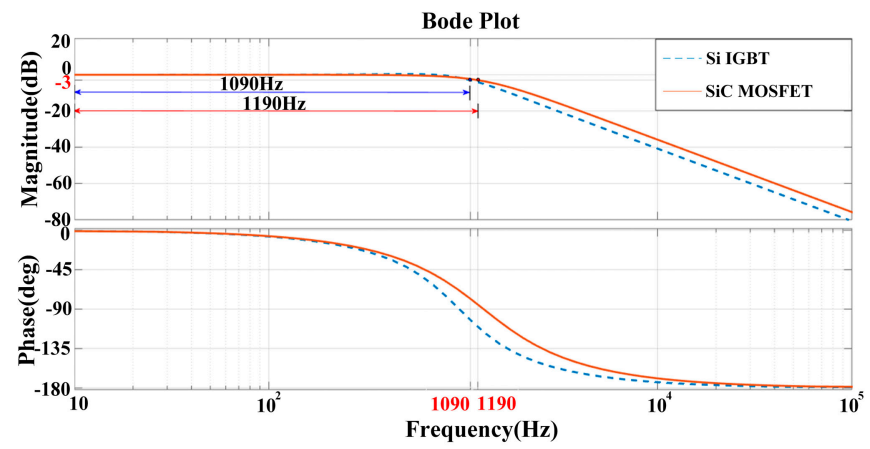

Figure 7. Bode plot of the inverter fed PMSM system with different power devices.

\subsection{Relative Stability Analysis}

In the process of motor control system design, stability is a necessary condition for the control system to work properly. Additionally, the control system should also have a high level of relative stability. During the operation of a PMSM system, accumulated losses will lead to an increase in temperature. Furthermore, changes in the temperature affect the stator resistance $R_{\mathrm{a}}$ and $q$-axis inductance $L_{\mathrm{q}}$, which are likely to destroy the stability of the whole system.

Based on the Nyquist criterion, when the open-loop transfer function of the control system has no pole in the right part of the S-plane, and the open-loop frequency characteristic curve $G(j \omega)$ passes through the point $(-1, j 0)$, the control system is at the critical stable edge. In this case, if the control system parameters drift, and it is possible to make open-loop frequency characteristic curve of the control system surround the point $(-1, j 0)$, resulting in the control system instability.

In control theory, the stability margins which include the phase margin and amplitude margin are evaluation indexes of the relative stability of the system. The phase- and amplitude-margins of the system determine the stability of the dynamic performance.

From the open-loop transfer function $G(s)$ of the drive system in (9), the frequency characteristic $G(j \omega)$ can be obtained as:

$$
G(j \omega)=\omega_{n}^{2} /\left(j \omega\left(j \omega+2 \xi \omega_{n}\right)\right)
$$

The amplitude-frequency characteristic $A(\omega)$ and the phase-frequency characteristic $\phi(\omega)$ are:

$$
\begin{array}{r}
\mathrm{A}(\omega)=\omega_{n}^{2} /\left(\omega \sqrt{\omega^{2}+\left(2 \xi \omega_{n}\right)^{2}}\right) \\
\varphi(\omega)=-90^{\circ}-\arctan \left(\omega / 2 \xi \omega_{n}\right)
\end{array}
$$

When the open-loop amplitude-frequency characteristic of a system is equal to 1, i.e., $A(\omega)=|G(j \omega)|=1$, the corresponding frequency is defined as the open-loop cut-off frequency $\omega_{\mathrm{c}}$. The difference between the phase angle $\phi\left(\omega_{\mathrm{c}}\right)$ and $-180^{\circ}$ at the open-loop cut-off frequency represents the phase margin $\gamma$ of the system, that is:

$$
20 \lg \left|G\left(j \omega_{c}\right)\right|=0(\mathrm{~dB})
$$




$$
\gamma=180^{\circ}+\varphi\left(\omega_{\mathrm{c}}\right)
$$

According to (19) and (21), the open-loop cut-off frequency can be calculated as:

$$
\omega_{\mathrm{c}}=\omega_{\mathrm{n}} \sqrt{-2 \xi^{2}+\sqrt{4 \xi^{2}+1}}
$$

And the phase margin $\gamma$ can be derived from (22):

$$
\gamma=\arctan \frac{2 \xi}{\sqrt{\sqrt{4 \xi^{4}+1}-2 \xi^{2}}}=\arctan \frac{1}{\sqrt{-1 / 2+1 / 4 \sqrt{4+1 / \xi^{4}}}}
$$

It is observed that the phase margin is only related to the arctangent function, the phase margin increases with an increase of damping ratio $\xi$. From (15), the damping ratio $\xi_{1}$ of the SiC-drive system is larger than that of the Si-drive system $\xi_{2}$, which results in a larger phase margin in SiC-drive system.

When the open-loop frequency characteristic curve of the system intersects with the negative real axis, i.e., $\phi(\omega)=-180^{\circ}$, the corresponding frequency can be obtained by (20), known as the phase cross-over frequency $\omega_{\mathrm{g}}$ :

$$
\omega_{\mathrm{g}}=2 \xi \omega_{n} \cdot \tan 90^{\circ}=n \cdot 2 \xi \omega_{n}
$$

where, $n$ tends to infinity.

At $\omega_{\mathrm{g}}$, the reciprocal of the open-loop amplitude-frequency characteristic $A\left(\omega_{\mathrm{g}}\right)$ is defined as the amplitude margin $K_{\mathrm{g}}$ of the drive system:

$$
K_{\mathrm{g}}=1 / A\left(\omega_{\mathrm{g}}\right)=1 /\left|G\left(j \omega_{\mathrm{g}}\right)\right|
$$

According to (19) and (26), the amplitude margin of a system can be calculated as;

$$
K_{\mathrm{g}}=4 n \omega_{n} \xi^{2} \sqrt{n^{2}+1}
$$

The amplitude margin of the second-order system also tends to infinity, which makes the comparison between the two systems impossible. In order to facilitate the comparison, it is assumed that the phase cross-over frequency $\omega_{\mathrm{g}}$ is the corresponding frequency of the phase-frequency characteristic $\phi(\omega)=-179^{\circ}$ replacing $\phi(\omega)=-180^{\circ}$. The amplitude margin at this scenario can be calculated as:

$$
K_{\mathrm{g}} \approx 4 \times 57^{2} \cdot \omega_{n} \xi^{2}
$$

Equations (14) and (15) show that the natural frequency $\omega_{n}$ and the damping ratio $\xi$ of the $\mathrm{SiC}$-drive system are higher than the counterparts of the Si-drive system. Hence, it is not difficult to draw the following conclusion from (28):

$$
K_{\mathrm{g} 1}>K_{\mathrm{g} 2}
$$

where $K_{\mathrm{g} 1}, K_{\mathrm{g} 2}$ represent the amplitude margin of $\mathrm{SiC}$ - and Si-drive system, respectively.

In order to figure out the phase- and amplitude-margins of the system, a Nichols plot is plotted using the transfer function of the drive system. Unlike the Bode plot, the Nichols plot presents both phase and magnitude information in one diagram.

In summary, due to the faster switching speed and lower voltage drop of the SiC MOSFET, the voltage distortion of the system is smaller. Consequently, the natural frequency and damping ratio in the second-order system transfer function of a SiC-drive system are larger than that of a Si-drive system, which yields larger phase- and amplitude-margins in the SiC-drive system. 
As shown in Figure 8, the phase- and amplitude-margins of the SiC-drive system are $67.63^{\circ}$ and $97.68 \mathrm{~dB}$, which is larger than the counterparts of the Si-drive system ( $59.18^{\circ}$ and $91.39 \mathrm{~dB}$, respectively). Hence, the relative stability of the $\mathrm{SiC}$-drive system is better.

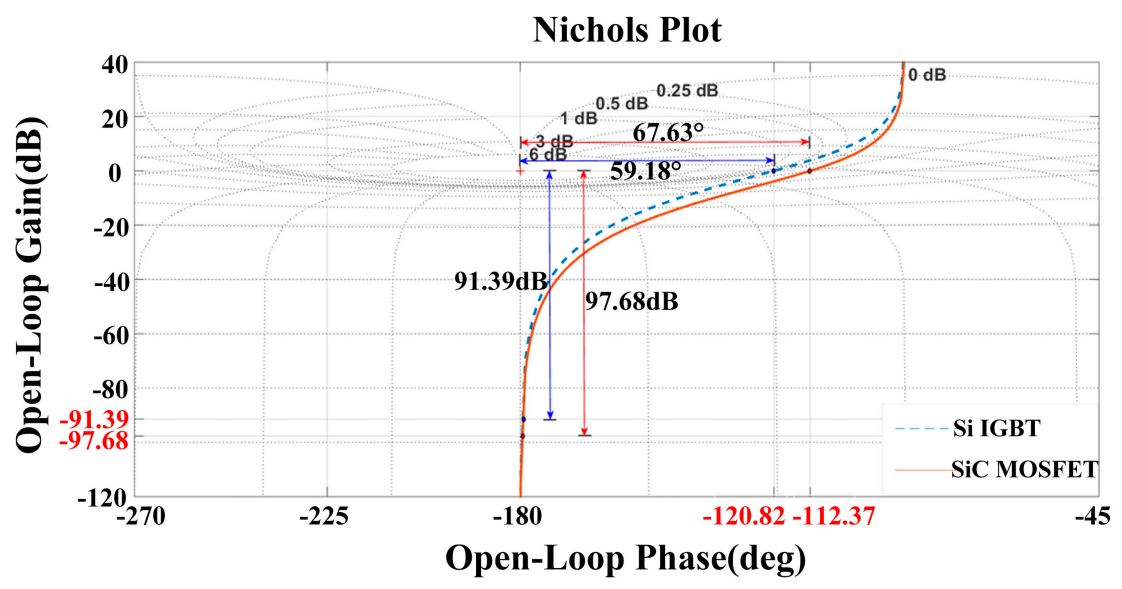

Figure 8. Nichols plot of the inverter fed PMSM system with different power devices.

\subsection{Robustness Analysis}

Robustness represents the sensitivity of the control system. In a case of a servo system, the robustness performance analysis is one of the fundamental issues in controller design. When the system is influenced by energy-bounded interference signals, such as system parameter variations due to varying load torque, the system robustness is a significant index to evaluate system performance.

Figure 9 shows a single-input-single-output (SISO) PMSM drive system with negative feedback-control. As the energy-bounded interference signal $u(\mathrm{~T})$ injected into the system, the controlled plant $G_{2}(s)$ transforms to $\widetilde{G}_{2}(s)$, as described by:

$$
\widetilde{G}_{2}(s)=G_{2}(s)+\Delta G_{2}(s)
$$

where $\Delta G_{2}(s)$ is the uncertain part of the plant which is assumed to satisfy the following equation:

$$
\left|\Delta G_{2}(j \omega)\right|<W_{\mathrm{T}}(\omega)
$$

where $W_{\mathrm{T}}(\omega)$ is a weighting function that represents the upper bound for the plant uncertainty. If the closed-loop system remains stability under such uncertain interferences, it is assumed that the feedback-control system is robust.

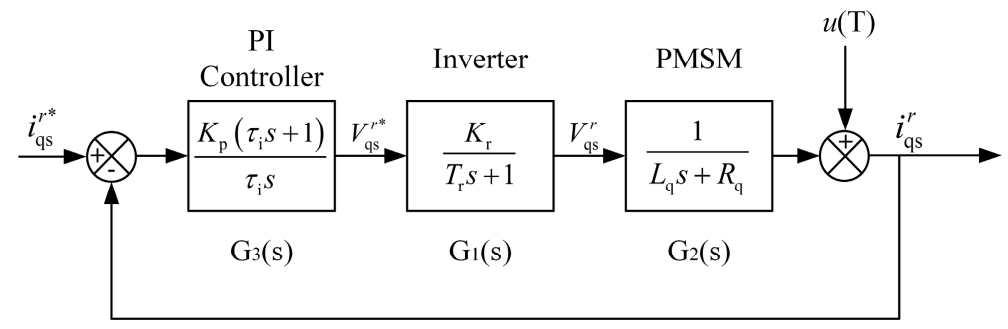

Figure 9. System block diagram with the disturbance injected. 
The variation rate of the transfer function of the system could be deduced by the following procedures: the errors of the open-loop and closed-loop transfer functions caused by changes of parameters could be expressed by (32) and (33), respectively:

$$
\begin{gathered}
\Delta G(j \omega)=G_{1}(j \omega) G_{3}(j \omega) \Delta G_{2}(j \omega) \\
\Delta G_{c}(j \omega)=\frac{G_{1}(j \omega) G_{3}(j \omega)\left(G_{2}(j \omega)+\Delta G_{2}(j \omega)\right)}{1+G_{1}(j \omega) G_{3}(j \omega)\left(G_{2}(j \omega)+\Delta G_{2}(j \omega)\right)} \\
-\frac{G_{1}(j \omega) G_{2}(j \omega) G_{3}(j \omega)}{1+G_{1}(j \omega) G_{2}(j \omega) G_{3}(j \omega)}
\end{gathered}
$$

Since $G_{1}(j \omega) \cdot G_{2}(j \omega) \cdot G_{3}(j \omega)>>G_{1}(j \omega) \cdot \Delta G_{2}(j \omega) \cdot G_{3}(j \omega)$, the (33) could be rewritten as:

$$
\Delta G_{\mathrm{c}}(j \omega)=\frac{\Delta G_{2}(j \omega) G_{1}(j \omega) G_{3}(j \omega)}{\left[1+G_{1}(j \omega) G_{2}(j \omega) G_{3}(j \omega)\right]^{2}}
$$

Combining (9), (10), (32) and (34), the variation rate of the transfer function of the system is derived, as expressed by following equation:

$$
\begin{gathered}
\Delta G_{\mathrm{c}}(j \omega) / G_{\mathrm{c}}(j \omega)=S(j \omega) \cdot \Delta G(j \omega) / G(j \omega) \\
S(s)=1 /\left(1+G_{1}(s) G_{2}(s) G_{3}(s)\right)
\end{gathered}
$$

In the robustness analysis, the sensitivity function $S(\mathrm{~s})$ is an essential index, which reflects the ratio of the relative deviation $\Delta G(j \omega) / G(j \omega)$ of the open-loop characteristics to the gain of the closed-loop frequency characteristics $\Delta G_{\mathrm{c}}(j \omega) / G_{\mathrm{c}}(j \omega)$. When the value of $S(s)$ is small enough, the relative deviation of the closed-loop characteristics will be limited within the engineering allowance. Hence, the control system has a robustness capability under energy-bounded interferences.

In addition, $S(s)$ could also be defined as the ratio of the variation rate $\Delta G_{\mathrm{c}}(s) / G_{\mathrm{c}}(s)$ of the transfer function to the variation rate $\Delta G_{2}(s) / G_{2}(s)$ of the controlled plant $G_{2}(s)$, as described by:

$$
\frac{\Delta G_{\mathrm{c}}(s) / G_{\mathrm{c}}(s)}{\Delta G_{2}(s) / G_{2}(s)}=\frac{1}{1+G_{1}(s) G_{2}(s) G_{3}(s)}=S(s)
$$

Equation (37) manifests that reducing the gain of $S(s)$ would result in the diminution of the adverse effect on control error of PMSM drive system caused by the interference $u(\mathrm{~T})$. The sensitivity function $S(s)$ provides a general description of the impact by feedback disturbances in the control system. The $S(s)$ of the PMSM drive system in this paper could be obtained as follows by substituting (10) into (37):

$$
S(s)=1 /\left(1+K_{\mathrm{q}} K_{\mathrm{r}} K_{\mathrm{p}} /\left(\tau_{\mathrm{r}} \tau_{\mathrm{i}} s^{2}+\tau_{\mathrm{i}} s\right)\right)
$$

According to the switching characteristic of the SiC MOSFET and Si IGBT analyzed above, the $\mathrm{SiC}$ MOSFET presents higher switching speed and lower voltage drop. The phase voltage distortion of the SiC MOSFET inverter system is lower than the counterpart of the Si IGBT inverter system. Thus, the gain of $\mathrm{SiC}$-drive system $K_{\mathrm{r} 1}$ is greater than that of the Si-drive system $K_{\mathrm{r} 2}$. Besides, as the delay time constant of an inverter defined in (2), it could be seen that the delay time constant of SiC-inverter $\tau_{\mathrm{r} 1}$ is less than that of the Si-inverter system $\tau_{\mathrm{r} 2}$.

In conclusion, with the greater inverter system gain $K_{\mathrm{r} 1}$ and lower inverter delay time $\tau_{\mathrm{r} 1}$, the sensitivity $S(s)$ of the $\mathrm{SiC}$-drive system is smaller. The preferable robustness performance of the $\mathrm{SiC}$-drive system is thus clarified.

\section{Experimental Analysis}

The impact of SiC MOSFETs on the dynamic performance of PMSM drive systems is further validated experimentally in a SiC-drive system, and the results were compared with those of the Si-drive system. 
The experimental setup is illustrated in Figure 10. In order to prevent unpredictable factors from impacting the voltage and current waveforms, the same control boards based on DSP28335, the same current sensors (LEM DHAB s/14) and same PMSM with a Tamagawa resolver (TS2640N321E64) are used in the two test drive systems. An AD2S1210 resolver-digital converter with a highest accuracy of $0.24 \mathrm{rpm}$ is adopted. The only difference is the power switching device: SiC MOSFET (CAS300M12BM2, Cree, 1200 V, 300 A) and Si IGBT (FF400R12KE3, Infineon, 1200 V, 400 A) are adopted.

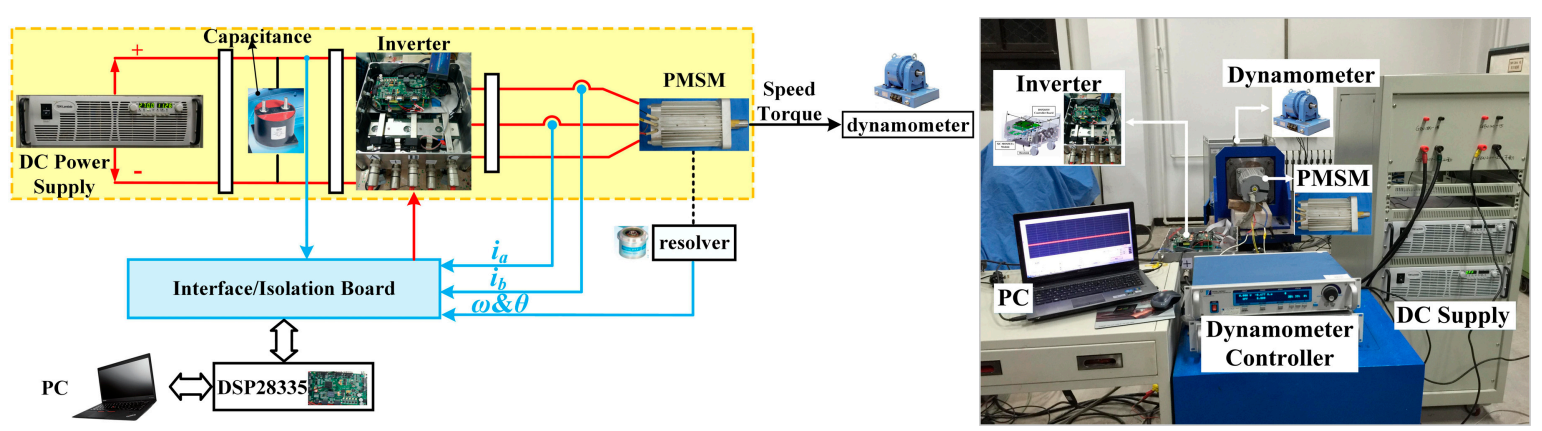

Figure 10. Experimental setup of the PMSM drive system.

\subsection{Fast Response Performance Results}

The same control strategy and PI parameters are set in the two systems, yielding a relative fair comparison. The speed controller is a conventional two-loop PI control. One is the inside loop, namely current loop. The corresponding $K_{\mathrm{p}}$ and $K_{\mathrm{i}}$ are 2.3 and 0.01 for the direct-axis current $i_{\mathrm{d}}$ separately. The $K_{\mathrm{p}}$ and $K_{\mathrm{i}}$ for the quadrature-axis current $i_{\mathrm{q}}$ are 2.5 and 0.005 , respectively. The other one is the outside loop, namely the speed loop. The corresponding $K_{\mathrm{p}}$ and $K_{\mathrm{i}}$ are 0.042 and 0.00035 , respectively. A series of bandwidths of q-axis currents are measured under different switching frequencies and dead times, and the effects of the different power devices on the bandwidth of PMSM drive system are explored. Additionally, the speed settling times of the two PMSM drive systems are investigated and compared as well.

\subsubsection{The $q$-Axis Current Tracking Experiments}

The references of sinusoidal current with different frequencies are assigned to the $\mathrm{SiC}$ - and Si-drive systems, respectively, and the loci of actual current tracking are recorded. As the frequency of the reference current increases, the phase difference between the reference and actual current increases, and the amplitude of the actual current waveform decreases. When the amplitude of actual current waveforms declines to 0.707 times the amplitude of the reference current, the corresponding frequency is defined as the bandwidth of the drive system.

Figure 11 shows the experimental results at a switching frequency of $15 \mathrm{kHz}$ and a dead time of $2 \mu \mathrm{s}$. Figure 11a shows experimental results of the $q$-axis reference current and the actual $q$-axis current when the frequency and the amplitude of the reference current are $545 \mathrm{~Hz}$ and $6 \mathrm{~A}$, respectively. The actual current of the $\mathrm{SiC}$-drive system presents $5.3 \mathrm{~A}$ amplitude and $53.8^{\circ}$ phase lag. Meanwhile, the actual current of the Si-IGBT system has $4.2 \mathrm{~A}$ amplitude and $116^{\circ}$ phase lag. The SiC-drive system manifests a faster dynamic response compared with the Si-drive system. 


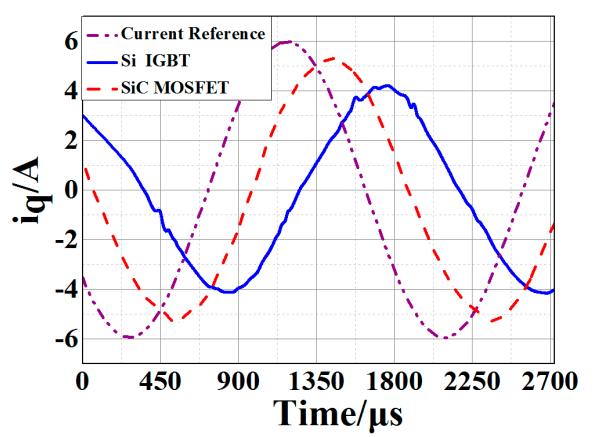

(a)

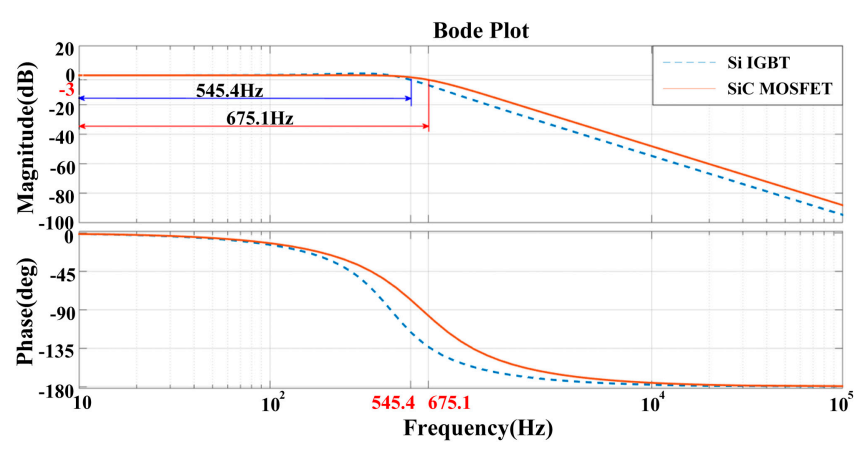

(b)

Figure 11. The $q$-axis current tracking experimental results. (a) Commanded and actual $q$-axis current.

(b) Bode plot of systems at $15 \mathrm{kHz}$ switching frequency and $2 \mu$ s dead time.

Besides, the loci of the current tracking of the two systems are recorded at a large scale of frequencies, then the Bode plot is obtained shown in Figure 11b. The bandwidth of the SiC-drive system is $675.1 \mathrm{~Hz}$, which is higher than that of the Si-drive system $(545.4 \mathrm{~Hz})$. Moreover, the current bandwidths of the two systems under different switching frequencies and dead times are comprehensively compared in Table 3.

Table 3. The frequency response results of $q$-axis current with different switching frequency and dead time.

\begin{tabular}{cccc}
\hline \multicolumn{2}{c}{ Variables } & \multicolumn{2}{c}{$\boldsymbol{q}$ Axis Current Bandwidth/Hz } \\
\hline Switching Frequency/kHz & Dead Time/ $\boldsymbol{\mu s}$ & SiC-Drive System & Si-Drive System \\
\hline \multirow{2}{*}{10} & 2 & 671.5 & 537.4 \\
& 3 & 663.4 & 526.3 \\
& 4 & 653.2 & 514.5 \\
\hline \multirow{2}{*}{15} & 2 & 675.1 & 545.4 \\
& 3 & 668.8 & 531.2 \\
& 4 & 658.5 & 524.9 \\
\hline
\end{tabular}

In accordance with the aforementioned analysis, faster switching speed, lower dead time, smaller voltage drop and output capacitance indeed result in a lower phase voltage distortion, and a higher bandwidth. Hence, the experimental results are consistent with the conclusions presented in Section 4 .

\subsubsection{The Step Response of the Speed Loop}

The references of step speed ( 0 to $100 \mathrm{rpm}$ ) are assigned to the two PMSM drive systems under no-load conditions. The speed response loci are captured under different switching frequencies and dead times. Figure 12a,b illustrate the experimental results of the Si- and SiC-drive systems, respectively, at $15 \mathrm{kHz}$ switching frequency and $2 \mu \mathrm{s}$ dead time. The setting time of the SiC-drive system is $59.51 \mathrm{~ms}$, which is less than that of the Si-drive system $(68.27 \mathrm{~ms})$. 


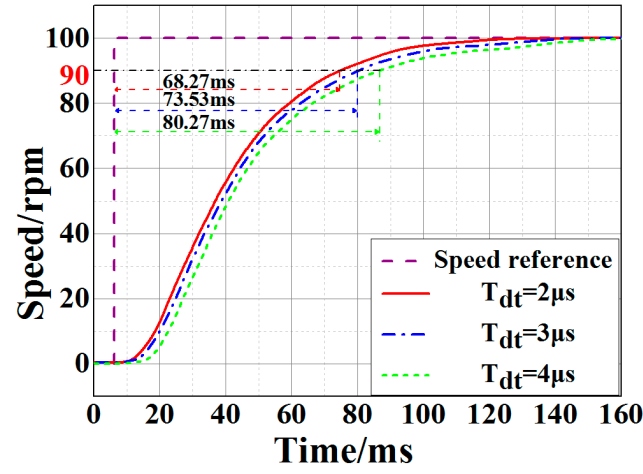

(a)

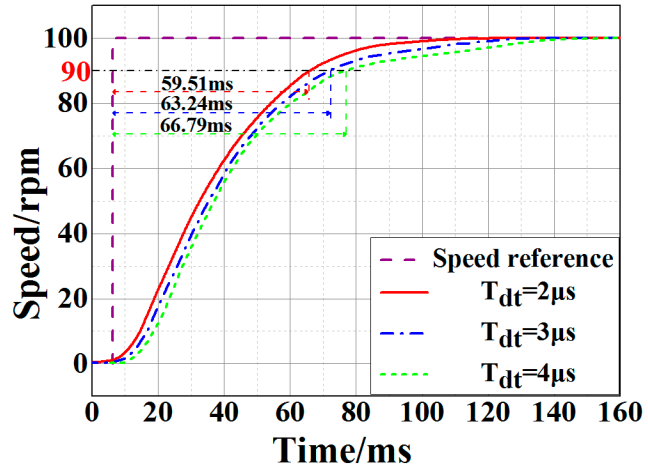

(b)

Figure 12. Step response of speed loop at $15 \mathrm{kHz}$ with different dead time; (a) Si IGBT based system; (b) SiC MOSFET based system.

Furthermore, the detailed experimental step response results of speed under different switching frequencies and dead times, are summarized in Table 4 . The settling time extends as the dead time increases and the switching frequency declines, which means the fast response performance of the drive system deteriorates.

Table 4. The step response results of speed loop with different switching frequency and dead time.

\begin{tabular}{cccc}
\hline Variables & & \multicolumn{2}{c}{ Settling Time $\boldsymbol{t}_{\mathbf{s}} / \mathbf{m s}$} \\
\hline Switching Frequency/kHz & Dead Time/ $\boldsymbol{\mu s}$ & SiC-Drive System & Si-Drive System \\
\hline \multirow{2}{*}{10} & 2 & 61.31 & 71.12 \\
& 3 & 64.95 & 75.61 \\
& 4 & 68.23 & 82.96 \\
\hline \multirow{2}{*}{15} & 2 & 59.51 & 68.27 \\
& 3 & 63.24 & 73.53 \\
& 4 & 66.79 & 80.27 \\
\hline
\end{tabular}

\subsection{Relative Stability Results}

In this section, the relative stabilities of the two drive systems are investigated by experiments. The Nichols plot is drawn based on the transfer function of the drive system and experiment as shown in Figure 13. The phase and amplitude margins of the SiC-drive system are $62.33^{\circ}$ and $99.82 \mathrm{~dB}$, respectively, while the counterparts of the Si-drive system are $51.83^{\circ}$ and $86.03 \mathrm{~dB}$. A significant improvement in relative stability by adopting SiC MOSFETs can be observed from the results. In addition, thanks to the superior characteristics of the SiC MOSFET, the phase and amplitude margins can be further increased by decreasing the dead time and the switching period, whereas, the phase and amplitude margins of the Si-drive system are penalized by its limited switching speed and operation frequency. 


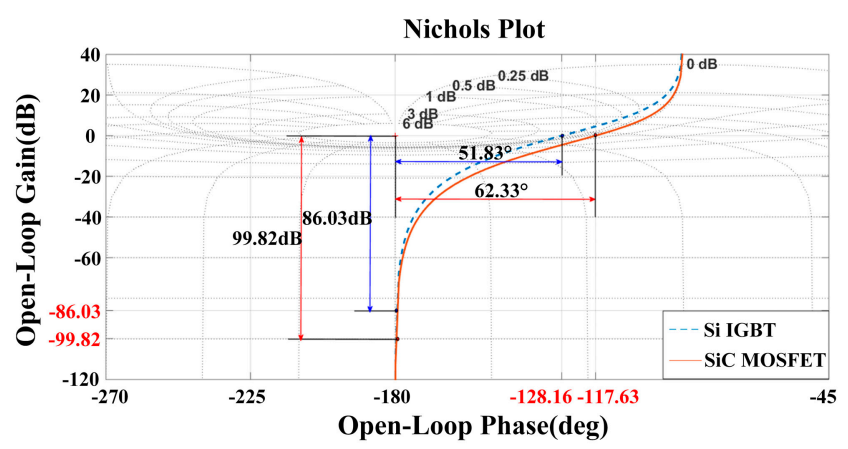

Figure 13. The Nichols plot of systems at $15 \mathrm{kHz}$ switching frequency and $2 \mu$ s dead time.

\subsection{Robustness Performance Results}

In order to evaluate the robustness performance of the drive system, an external torque is suddenly applied to the motor while the motor is operating at a steady-state. Figure 14 shows the experimental result.

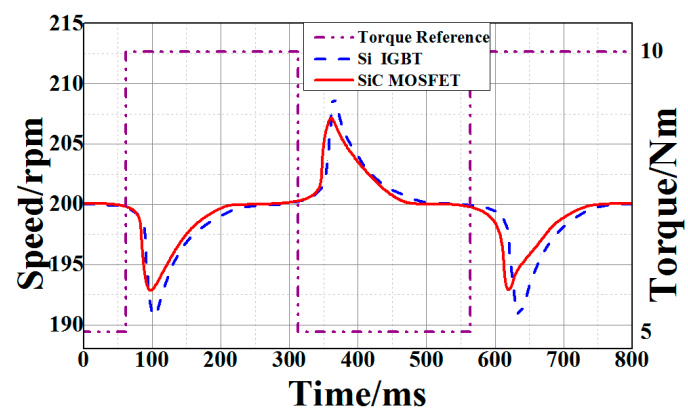

(a)

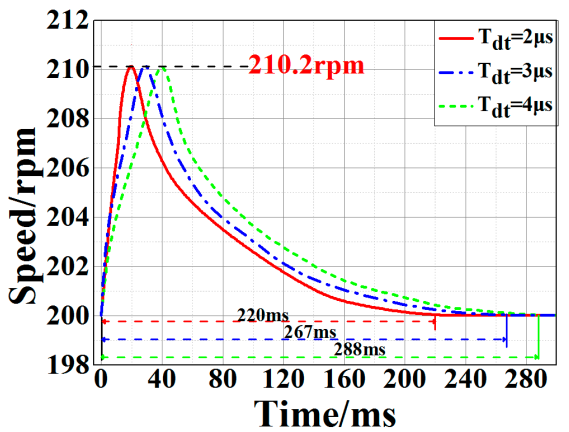

(b)

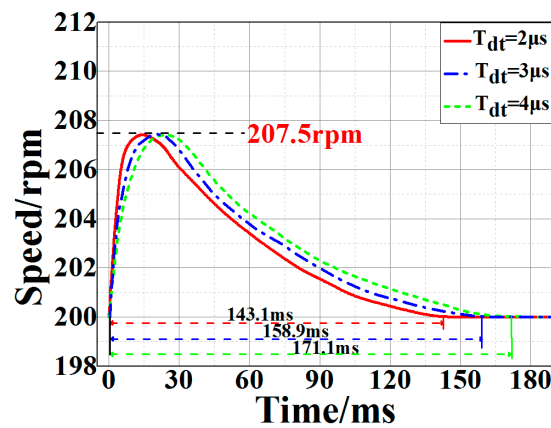

(c)

Figure 14. The real speed response curves with the external torque changes suddenly. (a) The fluctuations of the speeds at $15 \mathrm{kHz}$ switching frequency and $2 \mu$ s dead time; (b) The fluctuations of the speeds of Si-drive system with different dead times; (c) The fluctuations of the speeds of SiC-drive system with different dead times.

The real speed response curves are measured. The fluctuations of the speeds are due to the external torque changing abruptly from 5 to $10 \mathrm{Nm}$. Both the speed deviation and regulation restoration time of the SiC-drive system are smaller than the counterparts of the Si-drive system. The different switching frequencies and dead times are adopted to comprehensively investigate the robustness performance of the two drive systems. When the switching frequency and dead time are $15 \mathrm{kHz}$ and $2 \mu \mathrm{s}$ the speed deviation of the $\mathrm{SiC}$-drive system is $7.5 \mathrm{rpm}$, while the value of the Si-drive system is more than $10 \mathrm{rpm}$, as shown in Figure 14. Besides, the regulation restoration time of the $\mathrm{SiC}$ system is $143.1 \mathrm{~ms}$, which is 
less than that of the Si system ( $220 \mathrm{~ms}$ ). Hence, it is experimentally verified that the SiC-drive system achieves the better robustness performance to suppress the disturbance in the transient process.

It is worth mentioning that the turn-off time of the Si IGBT is increasing as temperature rises, which will increase the delay time constant $\tau_{\mathrm{r}}$ and decrease the gain $K_{\mathrm{r}}$ of the Si-inverter. Hence, the fast response, relative stability and robustness capability of the Si-drive system will be worse. On the contrary, the switching time of the SiC MOSFET is almost invariable under different temperatures. As a result, the SiC-drive system can maintain superior dynamic performance for a long-time operation.

\section{Conclusions}

In this paper, the impact of SiC MOSFETs on the dynamic performance of PMSM drive systems has been addressed. The transfer function of SiC-drive system was first developed taking into account the switching characteristics of the SiC MOSFETs. The Bode plot, the Nichols plot and the sensitivity function were developed to display the fast response, relative stability and robustness capability of the SiC-drive system, respectively. Both the analytical and experimental results manifested that the $\mathrm{SiC}$-drive system has higher dynamic performance features such as a faster response, a higher relative stability and more robustness than the Si-drive system counterpart. This study can be helpful for the applications of SiC MOSFETs in motor drive systems.

Acknowledgments: This work was supported in part by the National Natural Science Foundation of China under Project 51407004 and in part by the Aeronautical Science Foundation of China 20162851016.

Author Contributions: Xiaofeng Ding proposed the main idea for this paper and established the transfer functions of a PMSM drive system considering device characteristics with Min Du. Min Du and Feida Chen did the experiments. Min Du and Jiawei Cheng drew the figures. Hong Guo provided some useful suggestions in the construction of the paper framework. The paper was checked by Suping Ren. All authors carried out the theoretical analysis and contributed to writing the paper.

Conflicts of Interest: The authors declare no conflict of interest.

\section{References}

1. Zhang, H.; Tolbert, L.M. Efficiency impact of silicon carbide power electronics for modern wind turbine full scale frequency converter. IEEE Trans. Ind. Electron. 2011, 58, 21-28. [CrossRef]

2. Nakakohara, Y.; Otake, H.; Evans, T.M.; Yoshida, T. Three-Phase LLC Series Resonant DC/DC Converter Using SiC MOSFETs to Realize High-Voltage and High-Frequency Operation. IEEE Trans. Ind. Electron. 2016, 63, 2103-2110. [CrossRef]

3. Sung, W.; Baliga, B.J.; Huang, A.Q. Area-Efficient Bevel-Edge Termination Techniques for SiC High-Voltage Devices. IEEE Trans. Electron Devices 2016, 63, 1630-1636. [CrossRef]

4. Sarnago, H.; Lucía, Ó.; Burdío, J.M. A Comparative Evaluation of SiC Power Devices for High-Performance Domestic Induction Heating. IEEE Trans. Ind. Electron. 2015, 62, 4795-4804. [CrossRef]

5. Chen, Z.; Yao, Y.; Boroyevich, D.; Ngo, K. A 1200-V, 60-A SiC MOSFET multichip phase-leg module for high-temperature, high-frequency applications. IEEE Trans. Power Electron. 2014, 29, 2307-2320. [CrossRef]

6. Liu, S.; Gu, C.; Wei, J.; Qian, Q.; Sun, W.; Huang, A.Q. Repetitive Unclamped-Inductive-Switching-Induced Electrical Parameters Degradations and Simulation Optimizations for $4 \mathrm{H}-\mathrm{SiC}$ MOSFETs. IEEE Trans. Electron Devices 2016, 63, 4331-4338. [CrossRef]

7. Sarnago, H.; Lucía, Ó.; Mediano, A.; Burdío, J.M. Design and Implementation of a High-Efficiency Multiple-Output Resonant Converter for Induction Heating Applications Featuring Wide Bandgap Devices. IEEE Trans. Power Electron. 2014, 29, 2539-2549. [CrossRef]

8. Chen, Z. Characterization and Modeling of High-Switching-Speed Behavior of SiC Active Devices; Virginia Polytechnic Institute and State University: Blacksburg, VA, USA, 2009.

9. Zhao, T.; Wang, J.; Huang, A.Q.; Agarwal, A. Comparisons of SiC MOSFET and Si IGBT based motor drive systems. In Proceedings of the 2007 IEEE Conference Record of the 42nd IAS Annual Meeting Industry Applications Conference, New Orleans, LA, USA, 23-27 September 2007; pp. 331-335.

10. Ding, X.; Du, M.; Zhou, T.; Guo, H.; Zhang, C. Comprehensive comparison between silicon carbide MOSFETs and silicon IGBTs based traction systems for electric vehicles. Appl. Energy 2016, in press. [CrossRef] 
11. Xiong, R.; Sun, F.; Chen, Z.; He, H. A data-driven multi-scale extended Kalman filtering based parameter and state estimation approach of lithium-ion polymer battery in electric vehicles. Appl. Energy 2014, 113, 463-476. [CrossRef]

12. Zhang, Y.; Xiong, R.; He, H.; Shen, W. A lithium-ion battery pack state of charge and state of energy estimation algorithms using a hardware-in-the-loop validation. IEEE Trans. Power Electron. 2017, 32, 4421-4431. [CrossRef]

13. Antonopoulos, A.; Bangtsson, H.; Alakula, M.; Manias, S. Introducing a silicon carbide inverter for hybrid electric vehicles. In Proceedings of the Power Electronics Specialists Conference, Rhodes, Greece, 15-19 June 2008; pp. 1321-1325.

14. Mattavelli, P.; Tubiana, L.; Zigliotto, M. Torque-ripple reduction in PM synchronous motor drives using repetitive current control. IEEE Trans. Power Electron. 2005, 20, 1423-1431. [CrossRef]

15. Vafaie, M.H.; Dehkordi, B.M.; Moallem, P.; Kiyoumarsi, A. Minimizing torque and flux ripples and improving dynamic response of PMSM using a voltage vector with optimal parameters. IEEE Trans. Power Electron. 2016, 63, 3876-3888. [CrossRef]

16. Holtz, J.; Quan, J.; Pontt, J.; Rodriguez, J. Design of fast and robust current regulators for high-power drives based on complex state variables. IEEE Trans. Ind. Appl. 2004, 40, 1388-1397. [CrossRef]

17. Cho, Y.; Lee, K.B.; Song, J.H.; Lee, Y.I. Torque-ripple minimization and fast dynamic scheme for torque predictive control of permanent-magnet synchronous motors. IEEE Trans. Power Electron. 2015, 30, 2182-2190. [CrossRef]

18. Guo, X.; Wen, X.; Zhao, F.; Song, X.; Zhuang, X. PI parameter design of the flux weakening control for PMSM based on small signal and transfer function. In Proceedings of the 2009 IEEE International Conference on Electrical Machines and Systems (ICEMS 2009), Tokyo, Japan, 15-18 November 2009; pp. 1-6.

19. Guo, Y.; Xi, Z.; Cheng, D. Speed regulation of permanent magnet synchronous motor via feedback dissipative Hamiltonian realisation. IET Control Theory Appl. 2007, 1, 281. [CrossRef]

20. Senroy, N.; Suryanarayanan, S.; Steurer, M.; Woodruff, S.L. Adaptive transfer function estimation of a notional high-temperature superconducting propulsion motor. IEEE Trans. Ind. Appl. 2009, 45, 651-658. [CrossRef]

21. Keel, L.H.; Bhattacharyya, S.P. A bode plot characterization of all stabilizing controllers. IEEE Trans. Autom. Control 2010, 55, 2650-2654. [CrossRef]

22. Atsumi, T.; Messner, W.C. Modified bode plots for robust performance in SISO systems with structured and unstructured uncertainties. IEEE Trans. Control Syst. Technol. 2012, 20, 356-368. [CrossRef]

23. Malwatkar, G.M.; Khandekar, A.A.; Nikam, S.D. PID controllers for higher order systems based on maximum sensitivity function. In Proceedings of the 2011 3rd International Conference on Electronics Computer Technology (ICECT), Kanyakumari, India, 8-10 April 2011; Volume 1, pp. 259-263.

24. Belove, C. The sensitivity function in variability analysis. IEEE Trans. Reliab. 1966, 15, 70-76. [CrossRef]

25. Ohmae, T.; Matsuda, T.; Kamiyama, K.; Tachikawa, M.A. Microprocessor-Controlled High-Accuracy Wide-Range Speed Regulator for Motor Drives. IEEE Trans. Ind. Electron. 1982, 1, 207-211. [CrossRef]

26. Blasko, V.; Kaura, V.; Niewiadomski, W. Sampling of discontinuous voltage and current signals in electrical drive: A system approach. IEEE Trans. Ind. Appl. 1998, 34, 1123-1130. [CrossRef]

27. Böcker, J.; Buchholz, O. Can oversampling improve the dynamics of PWM controls? In Proceedings of the 2013 IEEE International Conference on Industrial Technology (ICIT), Cape Town, South Africa, 25-28 February 2013; pp. 1818-1824.

28. Alexandrou, A.D.; Adamopoulos, N.K.; Kladas, A.G. Development of a Constant Switching Frequency Deadbeat Predictive Control Technique for Field-Oriented Synchronous Permanent-Magnet Motor Drive. IEEE Trans. Ind. Electron. 2016, 63, 5167-5175. [CrossRef]

29. Lin-Shi, X.; Morel, F.; Llor, A.M.; Allard, B. Implementation of Hybrid Control for Motor Drives. IEEE Trans. Ind. Electron. 2007, 54, 1946-1952. [CrossRef]

30. Quang, N.K.; Hieu, N.T.; Ha, Q.P. FPGA-Based Sensorless PMSM Speed Control Using Reduced-Order Extended Kalman Filters. IEEE Trans. Ind. Electron. 2014, 61, 6574-6582. [CrossRef]

31. Idkhajine, L.; Monmasson, E.; Naouar, M.W.; Prata, A. Fully Integrated FPGA-Based Controller for Synchronous Motor Drive. IEEE Trans. Ind. Electron. 2009, 56, 4006-4017. [CrossRef]

32. Horvat, R.; Jezernik, K.; Čurkovič, M. An Event-Driven Approach to the Current Control of a BLDC Motor Using FPGA. IEEE Trans. Ind. Electron. 2014, 61, 3719-3726. [CrossRef] 
33. Chou, M.C.; Liaw, C.M. Dynamic Control and Diagnostic Friction Estimation for an SPMSM-Driven Satellite Reaction Wheel. IEEE Trans. Ind. Electron. 2011, 58, 4693-4707. [CrossRef]

34. Kommuri, S.K.; Defoort, M.; Karimi, H.R.; Veluvolu, K.C. A Robust Observer-Based Sensor Fault-Tolerant Control for PMSM in Electric Vehicles. IEEE Trans. Ind. Electron. 2016, 63, 7671-7681. [CrossRef]

35. El-Sousy, F.F.M. Hybrid Ho-Based Wavelet-Neural-Network Tracking Control for Permanent-Magnet Synchronous Motor Servo Drives. IEEE Trans. Ind. Electron. 2010, 57, 3157-3166. [CrossRef]

36. Calleja, C.; López-de-Heredia, A.; Gaztañaga, H.; Aldasoro, L.; Nieva, T. Validation of a Modified Direct-Self-Control Strategy for PMSM in Railway-Traction Applications. IEEE Trans. Ind. Electron. 2016, 63, 5143-5155. [CrossRef]

37. Shyu, K.-K.; Lai, C.-K.; Tsai, Y.-W.; Yang, D.-I. A newly robust controller design for the position control of permanent-magnet synchronous motor. IEEE Trans. Ind. Electron. 2002, 49, 558-565. [CrossRef]

38. Ding, X.; Chen, F.; Du, M.; Guo, H.; Ren, S. Effects of silicon carbide MOSFETs on the efficiency and power quality of a microgrid-connected inverter. Appl. Energy 2016, in press.

39. Bedetti, N.; Calligaro, S.; Petrella, R. Self-Commissioning of Inverter Dead-Time Compensation by Multiple Linear Regression Based on a Physical Model. IEEE Trans. Ind. Appl. 2015, 51, 3954-3964. [CrossRef]

40. Krishnan, R. Permanent Magnet Synchronous and Brushless DC Motor Drives; CRC Press/Taylor \& Francis: Boca Raton, FL, USA, 2010.

(C) 2017 by the authors. Licensee MDPI, Basel, Switzerland. This article is an open access article distributed under the terms and conditions of the Creative Commons Attribution (CC BY) license (http:/ / creativecommons.org/licenses/by/4.0/). 